\title{
Early neurovascular retinal changes detected by swept-source OCT in type 2 diabetes and association with diabetic kidney disease
}

\author{
Monica Oliveira da Silva ${ }^{2,4^{*}} \mathbb{D}$, Anne Elise Cruz do Carmo Chaves ${ }^{2,4}$, Glauber Corrêa Gobbato ${ }^{2,6}$, \\ Mateus Augusto dos Reis ${ }^{3,4}$, Fabio Lavinsky ${ }^{2,5}$, Beatriz D'Agord Schaan ${ }^{3,4}$ and Daniel Lavinsky 1,2,4
}

\begin{abstract}
Purpose: To evaluate retinal thickness and capillary density in patients with type 2 diabetes (T2D) and their association with diabetic kidney disease (DKD) using swept-source optical coherence tomography (SS-OCT).

Methods: A cross-sectional study was conducted with T2D patients with mild or no diabetic retinopathy (DR) and nondiabetic controls. Inner retinal layer thickness was measured with SS-OCT. Retinal capillary density and the foveal avascular zone (FAZ) were measured with SS-OCT angiography (OCTA). SS-OCT parameters were compared in patients with and without diabetic kidney disease (DKD) and nondiabetic controls.

Results: 131 DKD eyes showed decreased ganglion cell layer plus $(G C L+)(p=0.005 \mathrm{Tl} ; p=0.022 \mathrm{l})$, retinal nerve fiber layer (RNFL) ( $p=0.003)$, and central retinal thickness (CRT) $(p=0.032)$, as well as foveal avascular zone (FAZ) enlargement ( $p=0.003$ ) and lower capillary density in the superficial vascular plexus ( $p=0.016$, central quadrant), compared to controls. No statistically significant changes were found between diabetic patients without significant DKD and controls.

Conclusion: Our findings suggest early neurovascular damage in patients with T2D; these changes were more significant in patients with DKD. Larger longitudinal studies are warranted to determine the role of early neurovascular damage in the pathophysiology of severe DR.
\end{abstract}

Keywords: Diabetes mellitus type 2, Glomerular filtration rate, Diabetic retinopathy, Optical coherence tomography, Retinal neurodegeneration

\section{Introduction}

Diabetic retinopathy (DR) is the leading cause of vision loss and the most important ocular complication of diabetes mellitus [1]. Major risk factors are duration of diabetes, chronic hyperglycemia, and hypertension [2]. Chronic hyperglycemia leads to increased oxidative stress, inflammation, and hypoxia, all of which induce changes to the retinal neurovascular unit [3]. Diabetic

\footnotetext{
*Correspondence: cebiomonica@gmail.com

${ }^{4}$ Graduate Program in Endocrinology, Federal University of Rio Grande do Sul, UFRGS, Porto Alegre, Brazil

Full list of author information is available at the end of the article
}

retinopathy (DR) is classified clinically into a severity scale based on the presence of microaneurysms, hemorrhages, and vascular changes, such as venous beading, intraretinal microvascular abnormalities (IRMA), or neovascularization [4]. More advanced imaging technologies, such as optical coherence tomography (OCT), currently do not contribute to this classification, but they can detect early changes in retinal and vascular morphology in patients without DR or with mild DR [5].

Optical coherence tomography has become an important tool for management and follow-up of retinal diseases such as diabetic macular edema. Although most original author(s) and the source, provide a link to the Creative Commons licence, and indicate if changes were made. The images or other third party material in this article are included in the article's Creative Commons licence, unless indicated otherwise in a credit line to the material. If material is not included in the article's Creative Commons licence and your intended use is not permitted by statutory regulation or exceeds the permitted use, you will need to obtain permission directly from the copyright holder. To view a copy of this licence, visit http://creativecommons.org/licenses/by/4.0/. The Creative Commons Public Domain Dedication waiver (http://creativeco mmons.org/publicdomain/zero/1.0/) applies to the data made available in this article, unless otherwise stated in a credit line to the data. 
studies use the spectral domain OCT (SD-OCT), the recently introduced swept-source OCT (SS-OCT) has improved image penetration using a wavelength of $1050 \mathrm{~nm}$, higher imaging speeds (axial scan rate of 100,000 scans per second), higher detection efficiency, improved imaging range, and improved depth with reduced sensitivity roll-off that is capable of generating images of both the vitreous and choroid simultaneously [6]. SS-OCT is also capable of performing OCT angiography (OCTA), that uses the motion contrast generated by flowing erythrocytes to enable a noninvasive, dye-free, depth-resolved visualization of the retinal vasculature levels with high speed and eye tracking, which significantly decreases motion artifacts [7].

The role of retina neurodegeneration in the pathogenesis of microangiopathy remains unclear but recent studies pointed that diabetic neurodegenerative abnormalities could play an important role in the pathogenesis of early stages of DR in a large proportion patients T2D [8]. Lynch and Abràmoff reported functional and structural aspects of DR that precede clinical changes, such as neural apoptosis of ganglion, amacrine, and Müller cells, increased expression of glial fibrillary acidic protein (GFAP) in Müller cells, inflammatory glial activation, and increased expression of neurotrophic factors, such as basic fibroblast growth factor and ciliary neurotrophic factor [9].

Neuroretinal alterations in patients with diabetes without DR or with early-stage DR have been detected by OCT, and include decreased retinal nerve fiber layer (RNFL), ganglion cell layer (GCL), and inner plexiform layer (IPL) thickness [10]. Recent studies using SD-OCT and OCTA demonstrated that diabetic eyes could exhibit retinal and choroidal vascular alterations, potentially including perifoveal capillarity loss and choroidal thinning with volume loss, even before the occurrence of visible signs of DR $[11,12]$.

The term neurovascular unit (NVU) was first applied to the blood-brain barrier and, subsequently, to the retina, to describe the intricate communication between neurons, glial cells, and vascular cells that together coordinate the retinal vascular flow with metabolic activity [13]. The microvascular complications of diabetes affect the eyes and kidneys, and are associated with different risk factors such as diabetes duration and blood pressure and lipid control [14]. DR and diabetic renal neurodegeneration (DRN) are reported to have a strong association, and similar molecular pathways appear to be involved in the development of diabetic kidney disease (DKD) and retinal microvascular injury [15].

Therefore, the aim of this study was to detect structural and vascular retinal changes in patient with type 2 diabetes (T2D) with or without kidney disease (DKD) using SS-OCT and OCTA. Our hypothesis was that T2D and DKD would be associated with early neurovascular damage.

\section{Methods \\ Subjects}

This cross-sectional study was conducted at a public teaching hospital in Southern Brazil between July 2018 and July 2019. The protocol was reviewed and approved by the Hospital de Clínicas de Porto Alegre Ethical Committee (registration number 20180186), adhering to the tenets of the Declaration of Helsinki, and written informed consent was obtained from all patients.

The inclusion criteria were confirmed T2D according to the standards of the American Diabetic Association (ADA) [16], age above 45 years, and capacity to consent. The exclusion criteria were history of any significant ocular disease, previous diagnosis of glaucoma, previous eye surgery, spherical equivalent outside \pm 3 diopters, media opacities, clinical signs of moderate or severe DR or central macular edema, and previous bariatric surgery.

The control group was composed of health volunteers above 45 years old, who had recent (maximum 3 months) normal glycated hemoglobin (HbA1c) values $(<5.7 \%)$, no prior history of diabetes, and no prior or current history of kidney disease. Controls also could not present any ophthalmologic condition that could interfere on images evaluation as opacities and spherical equivalent outside \pm 3 diopters.

In the T2D group, DKD was defined by the presence of a urinary albumin concentration $(\mathrm{UAC})>14 \mathrm{mg} / \mathrm{L}$ and/or reduced estimated glomerular filtration rate (eGFR; $<60 \mathrm{~mL} / \mathrm{min} / 1.73 \mathrm{~m}^{2}$ ) [17]. Estimated glomerular filtration rate was calculated using the CKD-EPI (Chronic Kidney Disease Epidemiology Collaboration) equation [18], 19. To reduces the effects of diurnal variations, all examinations were carried out in the morning. T2D patients were divided into two groups according to kidney function: mild or no DKD (nDKD) (eGFR $\geq 60 \mathrm{~mL} /$ $\mathrm{min} / 1.73 \mathrm{~m}^{2}$ and/or $\mathrm{UAC}<14 \mathrm{mg} / \mathrm{L}$ or higher) and $\mathrm{DKD}$ $\left(\mathrm{eGFR}<60 \mathrm{~mL} / \mathrm{min} / 1.73 \mathrm{~m}^{2}\right.$ and $/$ or $\mathrm{UAC} \geq 14 \mathrm{mg} / \mathrm{L}$ ).

Both eyes of eligible T2D patients and controls were included in this study. All patients were subjected to a complete ophthalmologic examination that included slitlamp biomicroscopy, indirect ophthalmoscopy, fundus photography, best corrected visual acuity (BCVA), SSOCT, and OCTA. Age, gender, diabetes duration, HbA1c, and systemic hypertension were recorded. Diabetic retinopathy was graded by a masked experienced ophthalmologist as none, mild, moderate, severe nonproliferative, or proliferative, with or without macular edema, based on the International Clinical Diabetic Retinopathy 
classification system using fundus color images acquired with a Topcon DRI OCT Triton device [20].

\section{SS-OCT and OCTA Imaging}

SS-OCT and OCTA images were performed with a Triton DRI OCT plus scanner (Topcon, Tokyo, Japan), which uses a swept-source laser with a center wavelength of $1050 \mathrm{~nm}$ and scan speed of 100,000 A-scans per second. Images were analyzed using Triton Imaginet 6 (software version 1.22). In this study, the $3 \mathrm{D}(\mathrm{H})$ wide macula + line protocol was used with simultaneous color fundus picture of the posterior pole (Fig. 1). Before OCT imaging, pupils were dilated with tropicamide $0.5 \%$ at the same time of day to avoid diurnal variation.

All patients were evaluated through SS-OCT by an experienced ophthalmologist. OCT scans were excluded by the masked investigator if they showed signs of low quality or significant artifact. Choroidal/retinal thickness and vascular density measurements were obtained from an Early Treatment Diagnostic Retinopathy Study (ETDRS) grid centered at the fovea (diameters: center $1 \mathrm{~mm}$, inner circle $3 \mathrm{~mm}$, outer circle $6 \mathrm{~mm}$ ). Automated segmentation of retina and choroid was performed in nine ETDRS areas plus average thickness, center thickness, and total volume. Ganglion cell layer plus (GCL+), from nerve fiber layer (NFL)/ganglion cell layer (GCL) to inner plexiform layer (IPL)/inner nuclear layer (INL) and GCL++ complex, from inner NFL interface to IPL/INL, and retinal nerve fiber layer (RNFL) segmentation was performed in six standard areas: superior (S), nasal superior (NS), temporal superior (TS), inferior (I), temporal inferior (TI), and nasal inferior (NI), plus total volume. An active eye tracker was used to reduce motion artifact.

OCTA scans were acquired using the DRI OCT Triton system based on the Topcon OCT angiography ratio analysis (OCTARA) algorithm. OCTA software uses the proportion of bright pixels to the proportion of dark pixels to derive a measure of vascular density. Capillary density values were obtained by applying a $6 \mathrm{~mm} \times 6 \mathrm{~mm}$ ETDRS grid overlay centered at the fovea. Vascular density is derived from the percentage of the area occupied by bright pixels in a segmented area. Boundary layer segmentations were defined as superficial capillary plexus (SCP), from $2.6 \mu \mathrm{m}$ below internal limiting membrane to $15.6 \mu \mathrm{m}$ below the junction between IPL and INL (IPL/ INL); deep capillary plexus (DCP), from $15.6 \mu \mathrm{m}$ below the IPL/INL to $70.2 \mu \mathrm{m}$ below the IPL/INL; choriocapillaris $(\mathrm{CC})$, from Bruch's membrane (BM) (0- $\mu \mathrm{m}$ offset) to $10.4 \mu \mathrm{m}$ below the BM. Foveal avascular zone (FAZ) area $\left(\mu \mathrm{m}^{2}\right)$ was measured using manual delineation in
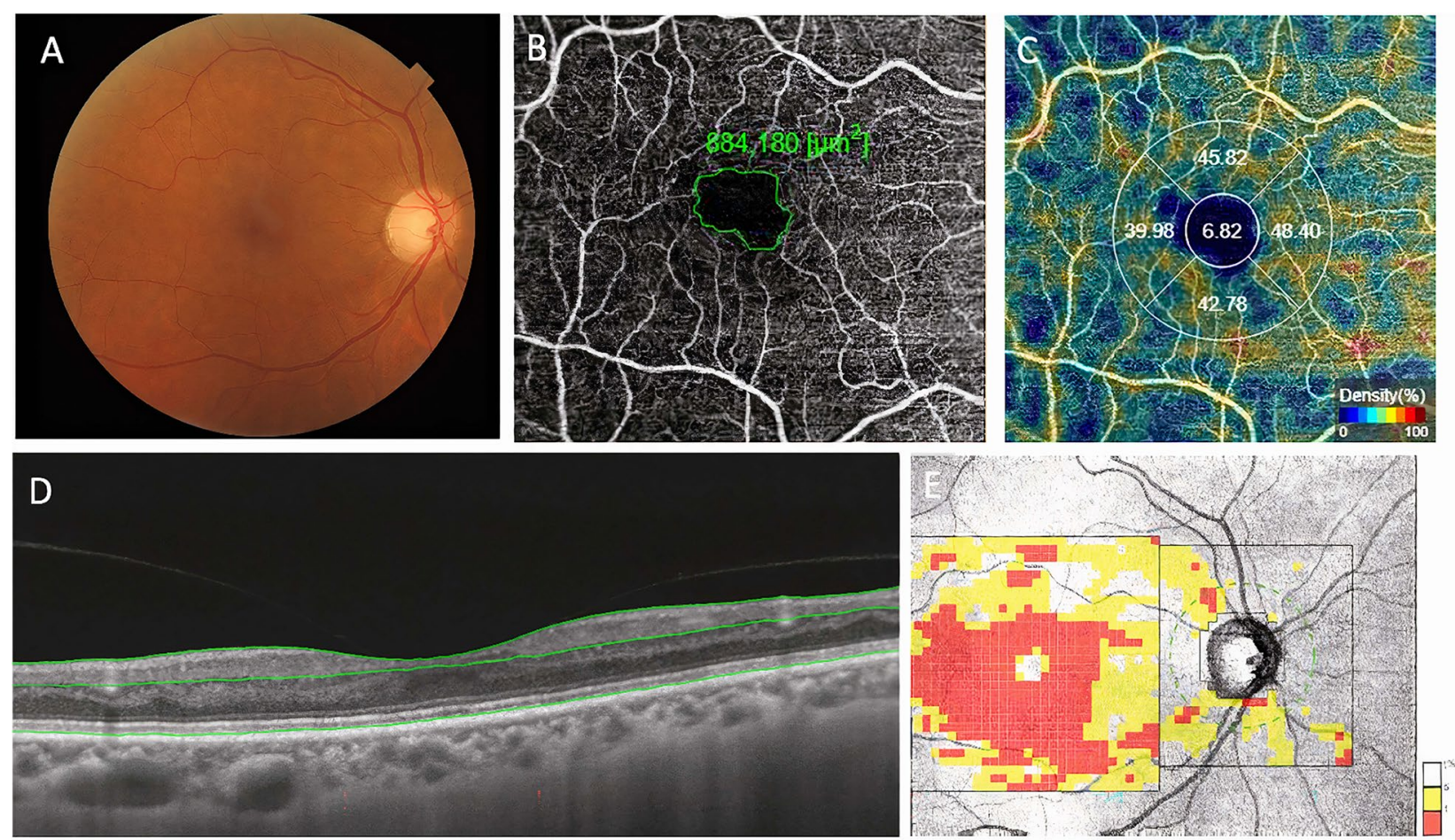

Fig. 1 Representative case of a T2D patient with no signs of diabetic retinopathy (DR) on color fundus photography (A). SS-OCT with OCT-A shows enlargement of the foveal avascular zone (B), decreased capillary density $(\mathbf{C})$ and thickness of inner retinal layers on structural OCT (D), and significant reduction of $\mathrm{GCL}+$ thickness $(\mathbf{E})$ 
the superficial and deep plexus using native SS-OCT software.

\section{Statistics}

Statistical analysis was performed using IBM SPSS software (version 26.0). Demographic and descriptive data were expressed as mean and standard deviation. For continuous variables, data were presented as the mean \pm standard deviation; categorical variables were

Table 1 Demographic and clinical characteristics of T2D patients with no or mild diabetic retinopathy vs controls

\begin{tabular}{lrcr}
\hline Variable & $\begin{array}{l}\text { T2D Group } \\
\text { (129 subjects) }\end{array}$ & $\begin{array}{l}\text { Control Group } \\
\text { (37 subjects) }\end{array}$ & p-value \\
\hline Gender, n (\%)* & & & \\
$\quad$ Male & $47(36.4 \%)$ & $13(36.6 \%)$ & $>0.999$ \\
$\quad$ Female & $82(63.3 \%)$ & $24(63.4 \%)$ & \\
Age in years, mean (SD) & $62.1( \pm 8.85)$ & $57.7( \pm 6.4)$ & $<\mathbf{0 . 0 0 1}$ \\
Ethnicity, n (\%) & & & \\
$\quad$ Caucasian & $111(85.9 \%)$ & $30(81.1 \%)$ & 0.090 \\
$\quad$ African descent/mixed & $18(14.1 \%)$ & $7(18.9 \%)$ & \\
BCVA, mean (SD) & $45.2( \pm 10.6)$ & $52.7( \pm 8.5)$ & $<\mathbf{0 . 0 0 1}$ \\
Hypertension (\%) & $120(93.2 \%)$ & $13(31.7 \%)$ & $<\mathbf{0 . 0 0 1}$ \\
HbA1C, mean (SD) & $8.3(1.6)$ & $5.5(0.3)$ & $<\mathbf{0 . 0 0 1}$ \\
\hline
\end{tabular}

Significant values in bold

$B C V A$, best corrected visual acuity

*Subjects presented as percentages. Differences between groups were assessed with generalized estimating equations (GEE) and were adjusted by age and use of both eyes, excluding missing values.

\section{Results}

Demographics and clinical characteristics of T2D patients and controls are summarized in Table 1. From 129 T2D patients, 258 eyes were included in the final analysis: 128 eyes of 64 subjects with mild or no DKD (nDKD), 130 eyes of 65 subjects with DKD, and 74 eyes of 37 controls. Diabetic patients were older, BCVA was lower in this group, and systemic hypertension was more prevalent than in controls. Among T2D subjects, we excluded 16 eyes due to moderate DR, 2 eyes with proliferative DR, 2 eyes with high opacity, 2 myopic eyes, 10 T1D eyes, and 2 MODY eyes.

Table 2 summarizes characteristics between T2D subjects with no or mild DKD and DKD. This comparison showed no difference in HbA1c $(8.2 \% \pm 1.6$ vs $8.4 \% \pm 1.6$, $\mathrm{p}=0.513)$, hypertension $(95.7 \%$ vs $91.5 \% \mathrm{p}=0.209)$, or age $(61.3 \pm 9.2$ vs $62.9 \pm 8.5, \mathrm{p}=0.144)$. Diabetic patients with DKD were more likely to have mild RD $(72.9 \%, \mathrm{p}<0.001)$, and higher UAC $(310.2 \pm 878.6 \mathrm{mg} / \mathrm{L}$, $\mathrm{p} \leq 0.001)$. They presented also longer duration of DM $(15.2 \pm 7.3$ years, $\mathrm{p}=0.010)$, worse BCVA $(43.7 \pm 10.9$ letters read, $\mathrm{p}=0.022)$, and lower eGFR values $\left(72.6 \pm 27.7 \mathrm{~mL} / \mathrm{min}\right.$ per $\left.1.73 \mathrm{~m}^{2}, \mathrm{p}<0.001\right)$.

Table 2 Demographic and clinical characteristics of patients with no or mild diabetic kidney disease (nDKD) and diabetic kidney disease (DKD) vs controls

\begin{tabular}{|c|c|c|c|}
\hline Variable ( $n=258$ eyes of 129 study participants & $n D K D$ ( $n=128$ eyes of 64 subjects) & DKD ( $n=130$ eyes of 65 subjects) & p-value \\
\hline \multicolumn{4}{|l|}{ Gender, n (\%)* } \\
\hline Male & $15(23.4 \%)$ & $32(49.6 \%)$ & \multirow[t]{2}{*}{$<0.001$} \\
\hline Female & 49 (76.6\%) & $33(50.4 \%)$ & \\
\hline Age in years, mean (SD) & $61.3( \pm 9.2)$ & $62.9( \pm 8.5)$ & 0.144 \\
\hline \multicolumn{4}{|l|}{ Ethnicity, n (\%)* } \\
\hline Caucasian & 55 (85.9\%) & $58(89.2 \%)$ & \multirow[t]{2}{*}{$<0.001$} \\
\hline African descent/mixed & $9(14.0 \%)$ & $7(10.8 \%)$ & \\
\hline \multicolumn{4}{|l|}{ Diabetic retinopathy stage, n (\%) } \\
\hline Without DR & $114(54.3 \%)$ & $96(45.7 \%)$ & \multirow[t]{2}{*}{$<0.001$} \\
\hline Mild NPDR & $13(27.1 \%)$ & $41(72.9 \%)$ & \\
\hline DM duration in years, mean (SD) & $12.8( \pm 6.4)$ & $15.2( \pm 7.3)$ & 0.010 \\
\hline $\mathrm{HbA} 1 \mathrm{c}$, mean (SD) & $8.2 \%( \pm 1.6)$ & $8.4 \%( \pm 1.6)$ & 0.513 \\
\hline $\mathrm{BCVA}$, mean (SD) & $47.1( \pm 10)$ & $43.7( \pm 10.9)$ & 0.022 \\
\hline Hypertension, n (\%) & $122(95.7 \%)$ & $119(91.5 \%)$ & 0.209 \\
\hline UAC (SD) & $8.2( \pm 5)$ & $310.2( \pm 878.6)$ & $<0.001$ \\
\hline eGFR (SD) & $89.3( \pm 14.0)$ & $72.6( \pm 27.7)$ & $<0.001$ \\
\hline
\end{tabular}

Significant values in bold

BCVA, best corrected visual acuity (number of letters read); UAC, urinary albumin concentration; eGFR, estimated glomerular filtration rate

*Subjects 
Table 3 Mean retinal layer thickness in T2D and controls

\begin{tabular}{|c|c|c|c|c|}
\hline \multirow[t]{2}{*}{ Retinal Layer Thickness, ETDRS $(\mu \mathrm{m})$} & \multirow{2}{*}{$\begin{array}{l}\text { T2D } \\
(n=258 \text { eyes of } 129 \\
\text { subjects) MD } \pm S D\end{array}$} & Controls & $95 \% \mathrm{Cl}$ & p-value \\
\hline & & \multicolumn{2}{|l|}{$\begin{array}{l}\text { ( } n=74 \text { eyes of } 37 \text { subjects) } \\
M D \pm S D\end{array}$} & \\
\hline \multicolumn{5}{|l|}{ Retina } \\
\hline Center Retinal Thickness (CRT) & $237.8( \pm 2.6)$ & $252.6( \pm 4.8)$ & -24.5 to -4.9 & 0.003 \\
\hline Total Volume & $7.9( \pm 0.04)$ & $8.1( \pm 0.1)$ & -0.4 to -0.1 & 0.002 \\
\hline Inner Temporal (IT) & $293.1( \pm 1.7)$ & $307.9( \pm 3.5)$ & -17.3 to -2.4 & 0.010 \\
\hline Inner Superior (IS) & $309.9( \pm 1.7)$ & $321.6( \pm 3.1)$ & -18.6 to -4.9 & 0.001 \\
\hline Inner Nasal (IN) & $309.1( \pm 1.9)$ & $322.2( \pm 3.0)$ & -19.6 to -6.5 & 0.000 \\
\hline Inner Inferior (II) & $307.2( \pm 1.7)$ & $319.9( \pm 2.7)$ & -18.6 to -6.8 & 0.000 \\
\hline \multicolumn{5}{|l|}{$\mathrm{GCL}+$} \\
\hline Total & $70.4( \pm 0.6)$ & $73.8( \pm 1.0)$ & -5.6 to -1.2 & 0.003 \\
\hline Temporal Superior (TS) & $70.5( \pm 0.6)$ & $74.0( \pm 1.5)$ & -6.6 to -0.5 & 0.024 \\
\hline Superior (S) & $69.7( \pm 0.6)$ & $73.3( \pm 1.1)$ & -5.9 to -1.2 & 0.003 \\
\hline Nasal Superior (NS) & $73.5( \pm 0.6)$ & $76.6( \pm 1.0)$ & -5.4 to -0.9 & 0.007 \\
\hline Nasal Inferior (NI) & $71.4( \pm 0.7)$ & $75.0( \pm 1.0)$ & -6.0 to -1.2 & 0.003 \\
\hline Inferior (I) & $66.6( \pm 0.6)$ & $69.6( \pm 1.1)$ & -5.4 to -0.5 & 0.017 \\
\hline Temporal Inferior (TI) & $71.0( \pm 0.6)$ & $74.46( \pm 1.2)$ & -6.0 to -1.0 & 0.007 \\
\hline \multicolumn{5}{|l|}{ RNFL } \\
\hline Total & $105.5( \pm 1.0)$ & $110.0( \pm 1.4)$ & -7.9 to -1.3 & 0.007 \\
\hline Temporal (T) & $74.6( \pm 1.0)$ & $79.2( \pm 1.5)$ & -8.2 to -1.0 & 0.014 \\
\hline Temporal Superior (TS) & $136.6( \pm 1.8)$ & $146.1( \pm 2.9)$ & -16.3 to -2.9 & 0.005 \\
\hline Nasal Superior (NS) & $122.1( \pm 1.9)$ & $120.8( \pm 4.0)$ & -7.2 to 9.9 & 0.760 \\
\hline Nasal (N) & $88.9( \pm 1.2)$ & $92.7( \pm 2.2)$ & -8.7 to 1.1 & 0.132 \\
\hline Nasal Inferior (NI) & $137.1( \pm 2.4)$ & $140.0( \pm 3.9)$ & -12.0 to 6.2 & 0.534 \\
\hline Temporal Inferior (TI) & $140.8( \pm 1.9)$ & $149.8( \pm 2.8)$ & -15.7 to -2.3 & 0.008 \\
\hline
\end{tabular}

Significant values in bold

$\mathrm{GCL}+$, ganglion cell layer plus; RNFL, retinal nerve fiber layer

Retinal layers in patients with T2D were thinner than in controls in the following ETDRS locations (Table 3): inner retina, CRT, and total volume; GCL+ (all quadrants), GCL++(all quadrants), and RNFL total and temporally.

Mean capillary density values of superficial, deep plexus, and choriocapillaris are shown in Table 4. The superficial plexus of T2D patients presented lower capillary density compared to controls (central quadrant 95\% $\mathrm{CI},-3.8$ to $0.7, \mathrm{p}=0.004$ ), except in the inferior quadrant. There were no vascular differences detectable in the deep and choriocapillaris layers (central quadrant $95 \% \mathrm{CI},-2.5$ to $1.2 ; \mathrm{p}=0.841$ and $95 \% \mathrm{CI},-2.5$ to 0.4 ; $\mathrm{p}=0.155)$.

Significant FAZ enlargement was observed in the diabetic group compared with control eyes in the superficial (95\% CI, 31.1 to 108.8; $\mathrm{p}<0.001)$ and deep plexus $(95 \%$ CI, 21.8 to $79.1 ; \mathrm{p}=0.001$ ) (Table 4). Analyzed separately, only DKD sample showed significant results: superficial plexus $95 \%$ CI, 19.2 to $116.5 ; \mathrm{p}=0.003$ and deep plexus 95\% CI, 17.1 to 96.9; $\mathrm{p}=0.002$ (Table 5).
T2D patients with DKD has presented difference compared to controls, namely thinning of retinal central and inner temporal ETDRS quadrant, GCL+temporal inferior and inferior quadrants, $\mathrm{GCL}++$ temporal inferior quadrant, RNFL total, temporal, temporal superior, and temporal inferior quadrants. DKD and nDKD groups have presented independent differences compared to controls as registered on Table 5. However, we didn't find any statistically significant difference between only nDKD group and controls.

OCTA showed a lower capillary density in superficial plexus, central quadrant $(95 \% \mathrm{CI}-4.0$ to $-0.3 ; \mathrm{p}=0.016)$ in the DKD group compared to controls ( $95 \% \mathrm{CI}-4.2$ to $-0.3 ; \mathrm{p}=0.020$ ) (Fig. 2). No changes were observed in any groups regarding the deep vascular plexus $(\mathrm{p}=0.762)$ and choriocapillaris $(\mathrm{p}=0.208)$.

\section{Discussion}

The inner retinal layers can be those most affected by diabetes, with reduction of thickness before clinically detectable vascular damage or in the early stages of DR. 
Table 4 Mean OCT-A capillary density in T2D vs control groups

\begin{tabular}{|c|c|c|c|c|}
\hline Vascular capillary plexus & $\begin{array}{l}\text { T2D Group } \\
\text { ( } n=258 \text { eyes of } 129 \text { subjects) } \\
M D \pm S D\end{array}$ & $\begin{array}{l}\text { Control Group } \\
\text { ( } n=74 \text { eyes of } 37 \text { subjects) } \\
M D \pm S D\end{array}$ & $95 \% \mathrm{Cl}$ & p-value \\
\hline \multicolumn{5}{|l|}{ Superficial } \\
\hline Superficial Central (SC) & $18.8( \pm 0.4)$ & $21.0( \pm 0.6)$ & -3.8 to -0.7 & 0.004 \\
\hline Superficial superior (SS) & $47.2( \pm 0.3)$ & $48.9( \pm 0.5)$ & -2.8 to -0.5 & 0.004 \\
\hline Superficial Nasal (SN) & $43.4( \pm 0.3)$ & $44.7( \pm 0.5)$ & -2.4 to -0.1 & 0.034 \\
\hline Superficial Inferior (SI) & $46.1( \pm 0.3)$ & $47.3( \pm 0.6)$ & -2.5 to 0.1 & 0.081 \\
\hline Superficial Temporal (ST) & $45.5( \pm 0.2)$ & $46.4( \pm 0.4)$ & -1.8 to -0.03 & 0.041 \\
\hline \multicolumn{5}{|l|}{ Deep } \\
\hline Deep Central (DC) & $18.0( \pm 0.5)$ & $18.6( \pm 0.8)$ & -2.5 to 1.2 & 0.481 \\
\hline Deep superficial (DS) & $51.5( \pm 0.3)$ & $50.7( \pm 0.5)$ & -0.3 to 1.9 & 0.163 \\
\hline Deep Nasal (DN) & $48.1( \pm 0.2)$ & $48.7( \pm 0.5)$ & -1.6 to 0.4 & 0.270 \\
\hline Deep Inferior (DI) & $50.6( \pm 0.3)$ & $50.2( \pm 0.6)$ & -0.9 to 1.8 & 0.499 \\
\hline Deep Temporal (DT) & $48.0( \pm 0.2)$ & $47.6( \pm 0.4)$ & -0.45 to 1.23 & 0.364 \\
\hline \multicolumn{5}{|l|}{ Choriocapillaris (CC) } \\
\hline Central & $48.7( \pm 0.36)$ & $49.8( \pm 0.7)$ & -2.5 to 0.4 & 0.155 \\
\hline Superficial & $53.0( \pm 0.1)$ & $53.0( \pm 0.3)$ & -0.6 to 0.6 & 0.982 \\
\hline Nasal & $52.8( \pm 0.2)$ & $53.4( \pm 0.3)$ & -1.3 to -0.02 & 0.042 \\
\hline Inferior & $53.0( \pm 0.2)$ & $53.4( \pm 0.3)$ & -1.1 to 0.3 & 0.270 \\
\hline Temporal & $53.1( \pm 0.2)$ & $53.2( \pm 0.2)$ & -0.7 to 0.4 & 0.569 \\
\hline \multicolumn{5}{|l|}{ FAZ (foveal avascular zone) } \\
\hline FAZ Superficial & $313.8( \pm 11.9)$ & $243.4( \pm 15.1)$ & 31.1 to 108.8 & $<0.001$ \\
\hline FAZ Deep & $188.5( \pm 10.1)$ & $137.1( \pm 10.4)$ & 21.8 to 79.1 & 0.001 \\
\hline
\end{tabular}

Most of this early damage can be detected using SD-OCT and enhanced depth imaging (EDI) mode. In our study, we used SS-OCT and OCTA to analyze retinal thickness and macular capillary density and the association of these findings with DKD in T2D patients and controls. Our results showed significant thinning of the inner retina of T2D patients, especially the GCL $+/++$ layer and RNFL; enlargement of the FAZ (both superficial and deep plexus); and lower capillarity in the superficial retinal plexus compared with controls. These findings suggest that neurovascular changes are an ongoing component of DR that may precede clinically moderate to severe microvascular changes.

The inner blood-retina barrier (iBRB) comprises the capillary endothelial cells which regulate blood flow in response to the metabolic demands of the retina, surrounded by pericytes, astrocytes and microglia; this complex is the neurovascular unit (NVU) [21]. iBRB integrity depends on the correct communication of the NVU component. Previous studies suggested that the retina in diabetes is subjected to successful adaptation to abnormal systemic conditions, followed by eventual loss of NVU function in response to progressive metabolic disruption, resulting in subtle clinical findings that could progress to advanced, vision-threatening retinopathy [22, 23].
Our study population with $\mathrm{T} 2 \mathrm{D}$ had a mean disease duration of $13.2 \pm 6.0$ years in the $\mathrm{nDKD}$ group and $15.0 \pm 8.0$ years in the DKD group. Mean levels of $\mathrm{HbA1c}$ were $8.4 \% \pm 1.8$ in subjects without DKD and $8.3 \% \pm 1.5$ in the DKD group, which represents a long period of hyperglycemia that appears to be sufficient to induce disruption of NVU elements, but more severe DR elements such as IRMA, venous beading, and neovascularization were absent. However, the T2D group showed a significantly worse BCVA compared to controls, which could reflect functional consequences of this early damage to the neuroretina. Bao et al. described visual field defects in patients with diabetes and no clinically detectable DR, and suggested that early neuroretinopathy could precede the classical microvascular disease [24].

Along with these neurodegenerative findings, OCTA images showed a decrease of capillary density in the superficial plexus of the retina and an enlargement of the FAZ in patients with T2D. Reduction of capillary density and FAZ disruption are findings related to reduction of blood flow, caused by microvascular damage diabetes These findings corroborate previous descriptions of microcirculatory impairment, both in retinal and choroidal vasculature of diabetic eyes, before more severe 
Table 5 Statistical differences between nDKD and DKD subgroups vs control group

\begin{tabular}{|c|c|c|c|c|c|c|c|}
\hline \multirow[t]{2}{*}{ Retinal layers } & \multirow{2}{*}{$\begin{array}{l}\text { Controls } \\
M D(\mu \mathrm{m}) \pm S D\end{array}$} & \multicolumn{3}{|c|}{$n D K D$ ( $n=128$ eyes of 64 subjects) } & \multicolumn{3}{|c|}{ DKD ( $n=130$ eyes of 65 subjects) } \\
\hline & & $\mathrm{MD}(\mu \mathrm{m}) \pm \mathrm{SD}$ & $95 \%$ IC & p value & $\mathrm{MD}(\mu \mathrm{m}) \pm \mathrm{SD}$ & $95 \%$ IC & p value \\
\hline \multicolumn{8}{|l|}{ Retina } \\
\hline Center (CRT) & $252.0 \pm 4.4$ & $239.1 \pm 3.3$ & -25.9 to 0.3 & 0.059 & $237.1 \pm 3.3$ & -28.7 to -0.9 & 0.032 \\
\hline Total Volume & $8.1 \pm 0.1$ & $7.8 \pm 0.1$ & -0.5 to -0.1 & 0.005 & $7.9 \pm 0.06$ & -0.4 to -0.02 & 0.025 \\
\hline Inner Temporal & $308.3 \pm 3.5$ & $298.5 \pm 2.3$ & -19.7 to 0.3 & 0.061 & $297.5 \pm 2.6$ & -20.7 to -0.7 & 0.032 \\
\hline Inner Superior & $321.8 \pm 3.1$ & $309.6 \pm 2.4$ & -21.6 to -2.7 & 0.006 & $310.1 \pm 2.6$ & -21.0 to -2.3 & 0.008 \\
\hline Inner Nasal & $322.2 \pm 2.8$ & $309.9 \pm 2.5$ & -21.3 to -3.2 & 0.003 & $308.3 \pm 3.0$ & -23.1 to -4.6 & 0.001 \\
\hline Inner Inferior & $320.0 \pm 2.6$ & $307.8 \pm 2.3$ & -20.3 to -4.1 & 0.001 & $306.6 \pm 2.6$ & -21.9 to -4.9 & 0.001 \\
\hline \multicolumn{8}{|l|}{$\mathrm{GCL}+$} \\
\hline Total & $74.1 \pm 1.0$ & $70.7 \pm 0.7$ & -6.3 to -0.5 & 0.015 & $70.0 \pm 0.9$ & -7.2 to -0.9 & 0.006 \\
\hline Sup. Temporal & $74.3 \pm 1.5$ & $70.5 \pm 0.8$ & -7.9 to 0.2 & 0.072 & $70.3 \pm 0.9$ & -8.2 to 0.2 & 0.065 \\
\hline Superior & $73.6 \pm 1.1$ & $69.6 \pm 0.7$ & -7.1 to -0.8 & 0.008 & $69.6 \pm 0.8$ & -7.3 to -0.6 & 0.014 \\
\hline Sup. Nasal & $76.9 \pm 1.0$ & $73.4 \pm 0.8$ & -6.4 to 1.0 & 0.019 & $73.3 \pm 0.9$ & -6.8 to -0.3 & 0.024 \\
\hline Inf. Nasal & $75.3 \pm 1.0$ & $71.8 \pm 0.8$ & -6.5 to -0.4 & 0.018 & $70.8 \pm 1.0$ & -8.0 to -1.0 & 0.006 \\
\hline Inferior & $69.9 \pm 1.1$ & $67.1 \pm 0.7$ & -5.8 to 0.3 & 0.096 & $66.0 \pm 1.0$ & -7.3 to -0.4 & 0.022 \\
\hline Inf. Temporal & $74.8 \pm 1.1$ & $71.8 \pm 0.7$ & -6.2 to 0.31 & 0.090 & $70.0 \pm 1.0$ & -8.4 to -1.1 & 0.005 \\
\hline \multicolumn{8}{|l|}{ RNFL } \\
\hline Total & $110.5 \pm 1.3$ & $106.8 \pm 1.3$ & -8.2 to 0.7 & 0.131 & $103.9 \pm 1.5$ & -11.3 to -1.8 & 0.003 \\
\hline Temporal & $79.5 \pm 1.5$ & $76.0 \pm 1.3$ & -8.2 to 1.1 & 0.211 & $73.0 \pm 1.4$ & -11.7 to -1.3 & 0.009 \\
\hline Sup. Temporal & $146.8 \pm 2.8$ & $139.6 \pm 2.4$ & -15.9 to 1.5 & 0.148 & $133.3 \pm 2.7$ & -22.8 to -4.1 & 0.002 \\
\hline Inf. Temporal & $150.2 \pm 2.7$ & $144.2 \pm 2.4$ & -14.8 to 2.6 & 0.284 & $137.4 \pm 2.7$ & -22.3 to -3.3 & 0.004 \\
\hline Sup. Nasal & $121.1 \pm 3.9$ & $120.7 \pm 2.8$ & -11.9 to 11.0 & 1.000 & $123.3 \pm 2.5$ & -8.8 to 13.2 & 1.000 \\
\hline Nasal & $93.1 \pm 2.2$ & $90.5 \pm 1.7$ & -11.7 to 7.8 & 1.000 & $87.1 \pm 1.5$ & -12.4 to 0.4 & 0.075 \\
\hline Inf. Nasal & $140.9 \pm 3.8$ & $136.7 \pm 3.4$ & -16.1 to 7.7 & 1.000 & $136.9 \pm 3.3$ & -16.3 to 8.3 & 1.000 \\
\hline \multicolumn{8}{|l|}{ FAZ } \\
\hline Superficial & $241.8 \pm 15.8$ & $312.2 \pm 17.7$ & -117.8 to -23.4 & 0.004 & $313 \pm 14.5$ & -114.5 to -29.3 & 0.001 \\
\hline Deep & $133.0 \pm 10.5$ & $182.0 \pm 13.5$ & -83.4 to -14.7 & 0.005 & $194.0 \pm 10.5$ & -95.6 to -26.4 & 0.001 \\
\hline
\end{tabular}

Internal retina layers: $\mathrm{GCL}+$, ganglion cell layer plus; RNFL, retinal nerve fiber layer

Significant values in bold

findings of DR $[25,26]$, and add information about a possible association between signs of DKD and microvascular foveal changes that could indicate a higher risk for more severe DR.

Our findings suggest that reduction of superficial blood flow may be affecting primarily the ganglion cells and their axons (RNFL), corroborating that the NVU is subjected to early changes due to chronic hyperglycemia and that OCTA could be used along with fundus imagining for screening and follow-up of DR. These results can corroborate the potential of OCTA as a clinical tool for earlier detection of DR [25, 27].

RNFL was significantly thinner only among T2D patients with some degree of DKD, not in T2D patients without DKD or controls. A recent meta-analysis suggested that the retinal microvasculature signs can be associated with kidney diseases, provide significant data on concurrent kidney disease status and predict future risk for kidney disease development and progression [28].

The causal relationship between DR and DKD has already been more explored and evaluated. Most research data came from studies involving diabetic patients with DR diagnosed in more advanced stages (moderate to proliferative) [29, 30].

The scarcity of data on structural alterations in the retina of T2D patients with early DR or no DR and its link with kidney damage can be attributed, at least in part, to the sensitivity of the diagnostic devices used to examine for presence of DR, such as color fundus photography or fundoscopy. SS-OCT has a higher sensitivity than previous methods and offers a more accurate analysis of the retinal layers, even compared to SD-OCT [6]. Early anatomical and neurodegenerative changes in the retina in the absence of DR, or in its initial stages, can offer a new 


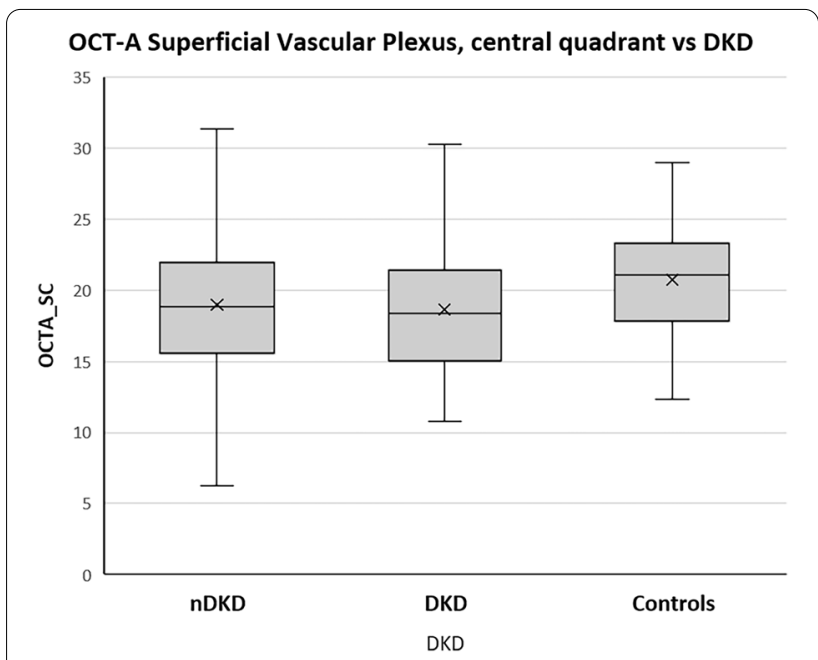

Fig. 2 Comparative capillary density (\%) of retinal superficial plexus between T2D nDKD and DKD subgroups and controls. The DKD subgroup showed significant loss of capillary density in the superficial central quadrant compared to controls

step to evaluate prognosis in the diabetic eye and even correlate it with kidney damage. According to Lynch and Abràmoff (2017), several lines of evidence now indicate that early neurophysiological and neurodegenerative changes should be considered as targets for therapy to supplement existing treatments for DR [9].

Our study had potential limitations, including its crosssectional design and limited sample (composed mainly of white women). Also, there are natural age-related changes and thinning of neuroretinal parameters [31], hence we minimized this effect by adjusting the statistical analysis by age.

We reported that patients with kidney microvascular damage (DKD group) showed more retinal neurovascular alterations compared to patients without kidney disease (nDKD). However, these results of a cross-sectional design do not allow us to establish a causal relationship between kidney disease and diabetic retinopathy and it remains unclear whether diabetic neurovascular changes are a predictive, modulating, or causative factor in DR.

Longitudinal studies are necessary to evaluate if presence of early retinal neurovascular changes is associated to an increased risk of kidney disease or if presence of diabetic kidney disease can drive a worse retinal prognosis or even both conditions run independently.

Longitudinal studies are also warranted to determine the role of these early neurovascular changes in predicting the development of severe non-proliferative and proliferative DR. These findings are potentially useful for screening, follow-up, and treatment of patients with T2D, and may positively impact their visual and systemic outcomes.

\section{Conclusion}

In conclusion, this study used swept-source structural OCT and OCTA and detected early changes in retinal thickness in the GCL+, GCL++, and RNFL, as well as FAZ enlargement and decrease of superficial retinal capillary density, in T2D patients-most notably, those with DKD-compared to controls. DKD was associated with inner retinal and superficial plexus vascular changes in T2D patients with mild or no DR, suggesting an association of eye and early kidney changes.

\section{Acknowledgements}

We thank the Ophthalmology and Endocrinology Unit of Hospital de Clinicas de Porto Alegre for their support and input for study recruitment; clinical research assistant Elisangela Soares for her valuable support in constructing the OCTA tables; and Vania Naomi Hirakata for her assistance with biostatistics.

\section{Authors' contributions}

MOS: Project elaboration, data collection, results analysis, manuscript writing. ACCC: Data collection. GGC: Data collection. MAR: Manuscript review. BDS: Manuscript review, results analysis. FL: Data collection, manuscript review, result analysis. DL: Project elaboration, data collection, results analysis, manuscript review. All authors read and approved the final manuscript.

\section{Authors' information}

$D L$ is associate editor of International Journal of Retina and Vitreous.

\section{Funding}

This project was partially supported by a research Investment Grant from the Hospital de Clínicas de Porto Alegre Research and Event Investment Fund (FIPE). The funder had no role in the design, conduct, analysis, or reporting of the study.

\section{Availability of data and materials}

Patient data are registered in patient medical charts and OCT device. According to Brazilian legal rules, data only can be accessed through patient or patient's legal representative permission.

\section{Declarations}

\section{Ethics approval and consent to participate}

The protocol was reviewed and approved by the Hospital de Clínicas de Porto Alegre Ethical Committee (registration number 2018-0186), adhering to the tenets of the Declaration of Helsinki, and written informed consent was obtained from all patients.

\section{Consent for publication}

Is contemplated in Informed Consent.

\section{Competing interests}

The authors report no conflicts of interest in this work.

\section{Commercial relationships policy/financial support}

Monica Oliveira da Silva, None;Anne Elise C. C. Chaves, None; Glauber C. Gobbato, None; Mateus A. dos Reis, None; Fabio Lavinsky, None; Beatriz D. Schaan, None; Daniel Lavinsky: Hospital de Clínicas de Porto Alegre Research and Event Investment Fund (FIPE).

\section{Author details}

${ }^{1}$ Department of Ophthalmology, Hospital de Clinicas de Porto Alegre, Federal University of Rio Grande do Sul, UFRGS, Porto Alegre, Brazil. ${ }^{2}$ Retina and Vitreous Research Center, Hospital de Clinicas de Porto Alegre, Porto Alegre, Brazil. ${ }^{3}$ Department of Endocrinology, Hospital de Clínicas de Porto Alegre, Porto Alegre, Brazil. ${ }^{4}$ Graduate Program in Endocrinology, Federal University of Rio Grande do Sul, UFRGS, Porto Alegre, Brazil. ${ }^{5}$ Medical School, UNISINOS University, Porto Alegre, Brazil. ' ${ }^{6}$ Lutheran University of Brazil Medical School, Porto Alegre, Brazil. 
Received: 2 September 2021 Accepted: 21 November 2021

Published online: 05 December 2021

\section{References}

1. Yau JW, Rogers SL, Kawasaki R, Lamoureux EL, Kowalski JW, BekT, et al. Global prevalence and major risk factors of diabetic retinopathy. Diabetes Care. 2012;35:556-64.

2. Solomon SD, Chew E, Duh EJ, Sobrin L, Sun JK, VanderBeek BL, Wykoff CC, Gardner TW. Diabetic Retinopathy: A Position Statement by the American Diabetes Association. Diabetes Care. 2017;40:412-8.

3. Das A, McGuire PG, Rangasamy S. Diabetic Macular Edema: Pathophysiology and Novel Therapeutic Targets. Ophthalmology. 2015;122:1375-94.

4. Flaxel CJ, Bailey ST, Fawzi A, Lim Jl, Adelman RA, et al. Diabetic Retinopathy Preferred Practice Pattern ${ }^{\circledR}$ American Academy of Ophthalmology. Diab Care. 2020;127:66-145.

5. Vujosevic S, Muraca A, Alkabes M, Villani E, Cavarzeran F, Rossetti L, De Cilla' S. Early microvascular and neural changes in patients with type 1 and type 2 diabetes mellitus without clinical signs of diabetic retinopathy. Retina. 2019;39:435-45.

6. Lavinsky F, Lavinsky D. Novel perspectives on swept-source optical coherence tomography. Int J Retina Vitreous. 2016;1(2):25.

7. Huang Y, Zhang Q, Thorell MR, An L, Durbin MK, Laron M, Sharma U, Gregori G, Rosenfeld PJ, Wang RK. Swept-source OCT angiography of the retinal vasculature using intensity differentiation-based optical microangiography algorithms. Ophthalmic Surg Lasers Imaging Retina. 2014;45:382-9.

8. Santos AR, Ribeiro L, Bandello F, Lattanzio R, Egan C, Frydkjaer-Olsen $U$ et al. ; European Consortium for the Early Treatment of Diabetic Retinopathy (EUROCONDOR). Functional and Structural Findings of Neurodegeneration in Early Stages of Diabetic Retinopathy: Cross-sectional Analyses of Baseline Data of the EUROCONDOR Project. Diabetes. 2017; 66:2503-2510.

9. Lynch SK, Abràmoff MD. Diabetic retinopathy is a neurodegenerative disorder. Vision Res. 2017;139:101-7.

10. van Dijk HW, Verbraak FD, Kok PH, Stehouwer M, Garvin MK, Sonka M DeVries JH, Schlingemann RO, Abràmoff MD. Early neurodegeneration in the retina of type 2 diabetic patients. Invest Ophthalmol Vis Sci. 2012;14(53):2715-9.

11. Farias LB, Lavinsky D, Benfica CZ, Lavisnky J, Canani LH. Microalbuminuria Is Associated With Early Retinal Neurodegeneration in Patients With Type 2 Diabetes. Ophthalmic Surg Lasers Imaging Retina. 2018;1(49):e36-43.

12. Dimitrova G, Chihara E, Takahashi H, Amano H, Okazaki K. Quantitative Retinal Optical Coherence Tomography Angiography in Patients With Diabetes Without Diabetic Retinopathy. Invest Ophthalmol Vis Sci. 2017;1(58):190-6.

13. Gardner TW, Davila JR. The neurovascular unit and the pathophysiologic basis of diabetic retinopathy. Graefes Arch Clin Exp Ophthalmol. 2017:255:1-6.

14. Romero-Aroca P, Mendez-Marin I, Baget-Bernaldiz M, Fernéndez-Ballart J, Santos-Blanco E. Review of the relationship between renal and retinal microangiopathy in diabetes mellitus patients. Curr Diabetes Rev. 2010;6:88-101.

15. Zhang J, Wang Y, Li L, Zhang R, Guo R, Li H, Han Q, Teng G, Liu F. Diabetic retinopathy may predict the renal outcomes of patients with diabetic nephropathy. Ren Fail. 2018;40:243-51.

16. Classification and Diagnosis of Diabetes. Standards of Medical Care. Am Diabetes Assoc Diabetes Care. 2020:43:S14-31.

17. Viana LV, Gross JL, Camargo JL, Zelmanovitz T, da Costa Rocha EP, Azevedo MJ. Prediction of cardiovascular events, diabetic nephropathy, and mortality by albumin concentration in a spot urine sample in patients with type 2 diabetes. J Diabetes Complications. 2012;26:407-12.

18. Skali H, Uno H, Levey AS, Inker LA, Pfeffer MA, Solomon SD. Prognostic assessment of estimated glomerular filtration rate by the new Chronic Kidney Disease Epidemiology Collaboration equation in comparison with the Modification of Diet in Renal Disease Study equation. Am Heart J. 2011:162:548-54

19. Soares AA, Prates AB, Weinert LS, Veronese FV, de Azevedo MJ, Silveiro SP. Reference values for glomerular filtration rate in healthy Brazilian adults. BMC Nephrol. 2013;28(14):54.
20. Wilkinson CP, Ferris FL 3rd, Klein RE, Lee PP, Agardh CD, Davis M, Dills D, Kampik A, Pararajasegaram R, Verdaguer JT. Proposed international clinical diabetic retinopathy and diabetic macular edema disease severity scales. Ophthalmology. 2003;110:1677-82.

21. Klaassen I, Van Noorden CJ, Schlingemann RO. Molecular basis of the inner blood-retinal barrier and its breakdown in diabetic macular edema and other pathological conditions. Prog Retin Eye Res. 2013;34:19-48.

22. Simó R, Stitt AW, Gardner TW. Neurodegeneration in diabetic retinopathy: does it really matter? Diabetologia. 2018:61:1902-12.

23. Abcouwer SF, Gardner TW. Diabetic retinopathy: loss of neuroretinal adaptation to the diabetic metabolic environment. Ann NY Acad Sci. 2014:1311:174-90.

24. Bao YK, Yan Y, Gordon M, McGill JB, Kass M, Rajagopal R. Visual field loss in patients with diabetes in the absence of clinically-detectable vascular retinopathy in a nationally representative survey. Investig Ophthalmol Vis Sci. 2019:60:4711-6.

25. Takase N, Nozaki M, Kato A, Ozeki H, Yoshida M, Ogura Y. Enlargement of foveal avascular zone in diabetic eyes evaluated by en face optical coherence tomography angiography. Retina. 2015;35:2377-83.

26. Kim M, Choi SY, Park YH. Quantitative analysis of retinal and choroidal microvascular changes in patients with diabetes. Sci Rep. 2018;8:12146.

27. Rosen RB, Andrade Romo JS, Krawitz BD, Mo S, Fawzi AA, Linderman RE, Carroll J, Pinhas A, Chui TYP. Earliest evidence of preclinical diabetic retinopathy revealed using optical coherence tomography angiography perfused capillary density. Am J Ophthalmol. 2019;203:103-15.

28. Aronov M, Allon R, Stave D, Belkin M, Margalit E, Fabian ID, Rosenzweig B. Retinal vascular signs as screening and prognostic factors for chronic kidney disease: a systematic review and meta-analysis of current evidence. J Pers Med. 2021;11(7):665.

29. Sasso FC, Pafundi PC, Gelso A, Bono V, Costagliola C, Marfella R, Sardu C, et al. Relationship between albuminuric CKD and diabetic retinopathy in a real-world setting of type 2 diabetes: findings from No blind study. Nutr Metab Cardiovasc Dis. 2019;29:923-30.

30. Boelter MC, Gross JL, Canani LH, Costa LA, Lisboa HR, Três GS, Lavinsky J, Azevedo MJ. Proliferative diabetic retinopathy is associated with microalbuminuria in patients with type 2 diabetes. Braz J Med Biol Res. 2006;39:1033-9.

31. Vianna JR, Danthurebandara VM, Sharpe GP, Hutchison DM, Belliveau AC, Shuba LM, Nicolela MT, Chauhan BC. Importance of Normal Aging in Estimating the Rate of Glaucomatous Neuroretinal Rim and Retinal Nerve Fiber Layer Loss. Ophthalmology. 2015;122:2392-8.

\section{Publisher's Note}

Springer Nature remains neutral with regard to jurisdictional claims in published maps and institutional affiliations.

Ready to submit your research? Choose BMC and benefit from

- fast, convenient online submission

- thorough peer review by experienced researchers in your field

- rapid publication on acceptance

- support for research data, including large and complex data types

- gold Open Access which fosters wider collaboration and increased citations

- maximum visibility for your research: over 100M website views per year

At BMC, research is always in progress.

Learn more biomedcentral.com/submissions 